\title{
Correction to "Curcumin Analog L48H37 Prevents Lipopolysaccharide-Induced TLR4 Signaling Pathway Activation and Sepsis via Targeting MD2"
}

In the above article [Wang Y, Shan X, Dai Y, Jiang L, Chen G, Zhang Y, Wang Z, Dong L, Wu J, Guo G, and Liang G (2015) J Pharmacol Exp Ther 353(3):539-550; DOI: https://doi.org/ 10.1124/jpet.115.222570], the incorrect chemical structure for L48H37 was displayed in the bottom of Fig. 1B. The chemical structure of L48H37 is correctly given in the abstract and in the list of abbreviations as 1-ethyl-3,5-bis((E)-3,4,5-trimethoxybenzylidene)piperidin-4-one. The correct image of the structure of 1-ethyl-3,5-bis((E)-3,4,5-trimethoxybenzylidene) piperidin-4-one is presented below.

The HTML and PDF versions of the article have been corrected.

The authors regret any inconvenience caused by this error.<smiles>CCN1C/C(=C\c2cc(OC)c(OC)c(OC)c2)C(=O)/C(=C/c2cc(OC)c(OC)c(OC)c2)C1</smiles>

L48H37

1-ethyl-3,5-bis $((E)-3,4,5-$

trimethoxybenzylidene)piperidin-4-one 